\title{
Sociologia da Juventude: da juventude desviante ao protagonismo jovem da Unesco
}

\author{
Breitner Tavares \\ Doutor em Sociologia (Universidade de Brasília) \\ Professor na Universidade de Brasília \\ btavareso2@gmail.com
}

\begin{abstract}
Resumo Neste artigo, discutem-se algumas abordagens teóricas para os estudos da juventude desenvolvidos pela Escola de Chicago, a teoria estrutural-funcionalista e os estudos culturais. Além disso, serão analisados alguns estudos pioneiros sobre juventude no Brasil. Esse panorama revela uma certa ênfase em estudos das juventudes das camadas médias e, por outro lado, uma certa ausência de pesquisas sobre juventude de classe trabalhadora. Esse quadro, por sua vez, sofrerá uma alteração a partir dos estudos da Unesco no final dos anos 90, ao assumirem uma demanda social por estudos sobre juventude. De fato, a Unesco, mobilizada duplamente por pesquisadores acadêmicos e gestores de políticas públicas, reimpulsiona esse campo de pesquisa, que atualmente assume um posição multidisciplinar.
\end{abstract}

Palavras-chave: estrutural-funcionalismo, estudos culturais, Sociologia da Juventude no Brasil, Unesco.

\section{Introdução}

A o se remeter à categoria juventude, objeto de diversas cono-

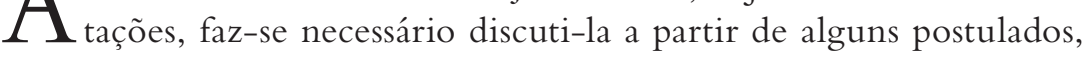
os quais ajudarão a se aproximar da configuração de um campo temático para o estudo sociológico da juventude, tais como: o conceito de gerações, a teoria funcionalista sobre juventude, os estudos culturais. Além disso, serão apresentados alguns elementos que serão a base para os primeiros estudos sobre a juventude no Brasil, no final dos anos 60 e durante a década de 1970. Além disso, discutem-se as contribuições da atual configuração do campo de estudos sobre a juventude, influenciado pela Unesco nos anos de 1990. Cabe destacar que esta abordagem pretende criar uma possibilidade de reflexão de como esses eixos demarcadores cunharam uma variedade de sentidos para a juventude.

\section{Sociologia da Juventude: alguns antecedentes}

Discutir alguns dos parâmetros formadores de um "campo" das pesquisas sociológicas sobre a juventude é, sem dúvida, uma tarefa complexa. Contudo, é relevante expor de maneira breve alguns de seus marcos definidores.

Os primeiros esforços dentro de um empirismo sociológico para realizar estudos sobre a juventude datam dos séculos XVIII. A função social da juventude era se integrar à sociedade maior, de modo a soli- 
dificá-la dentro de um sistema de valores prescritos. Isso implicava conhecer os limites das regras sociais que deveriam ser inculcadas desde o início da vida, dados pela psicologia e pelos primeiros estudos que tentavam seguir uma sistematicidade dita científica (Flitner, 1968).

A violência, fruto de um mundo em franca transformação, em função do industrialismo, acirrou problemas como a violência urbana nas suas diversas formas. A criminalidade juvenil, portanto, superava as marcas anteriores à modernidade. As principais hipóteses eram centradas nas camadas pobres. Diversas perspectivas de cunho psicologizante eram aplicadas no sentido de reidentificar as causas da delinquência jovem e as possíveis alternativas para sua superação (Flitner, 1968, p. 41).

Entretanto, no início do século XX, quando Stanley Hall publica sua obra Adolescense (1904), passa-se a uma abordagem de cunho psicogenético sobre a juventude. Sua tese aferia que aspectos biológicos seriam definidores da construção de uma personalidade jovem, para isso, o autor recorria a técnicas probabilísticas e estatísticas para suas generalizações. Contudo, as posições de Hall foram duramente criticadas por não admitirem a relevância da cultura como elemento na conformação das personalidades juvenis.

Nos anos 20, delineiam-se algumas reflexões fenomenológicas que propiciarão o surgimento do conceito de gerações. A princípio, destaca-se Eduard Spranger (1924), baseado nos estudos sobre hermenêutica de Wilhem Dilthey, que considera que os aspectos do comportamento psíquico do jovem devem ser articulados entre as pulsões internas de natureza biológica em conjunto com fatores de cunho social objetivos (Flitner, 1968). Mais adiante, Mannheim publica sua obra sobre gerações, em 1928, que representará um marco decisivo na constituição de um campo de estudos sobre a Sociologia da Juventude como parte de suas reflexões sobre sociologia do conhecimento e dos fatos culturais.

\section{As velhas teorias: Escola de Chicago (1920-1940) e teorias funcionalistas (1950-1960)}

No contexto norte-americano, em especial aquele relacionado à Escola de Chicago, destacam-se alguns autores como Thrasher (1927) e Shaw (1966) e Whyte (2005), autor de $A$ sociedade de esquina, obra que se refere ao estudo da juventude urbana, nos anos 30 do século XX. Nesse estudo, que foi realizado através do convívio com gangues de jovens filhos de imigrantes italianos em uma região segregada de Boston, o autor pôde desenvolver uma análise distinta das abordagens quantitativas que apontavam para conclusões de um quadro de anomia ou desvio social, realizadas até então sobre os processos de urbanização. $\mathrm{O}$ autor, a partir de uma extensa observação participante, conclui que o discurso que define essa juventude como desorganizada está equivocado. Para além dos conflitos presentes no espaço urbano, resultantes da pobreza e da falta de reconhecimento, a sociedade encontra-se em estado de fluxo, mas até esse fluxo traz um sentido de organização para os agentes sociais.

Posteriormente, outras abordagens, como em Parsons (1962), apostam no caráter de ordem estrutural. Elas discutem sobre a emergência da adolescência nas sociedades urbanas ocidentais, que ocorre a partir do fenômeno de desenvolvimento de um conjunto de padrões de comportamento que envolvem uma combinação em termos geracionais e elementos de papéis sexuais nos estilos bad boys, dos garotos, e glamour girls, das garotas. Esses jovens das classes médias norte-americanas expressam nas suas formas de interação, com outras gerações, novos elementos que permitiram a definição de uma "cultura juvenil" (Parsons, 1962, p. 606).

Como afirma Feixa (1999), o conceito de cultura juvenil trazia consigo uma definição homogênea de juventude em termos de classe social até o final da primeira metade do século passado. A juventude era vista sob uma perspectiva interclassista em relação à cultura hegemônica, na qual o enfoque na idade e a geração predominavam. Contudo, no mundo pós-Segunda Guerra Mundial, essa tendência dá lugar à ênfase na classe social para se compreender as culturas juvenis, que passam a ser abordadas numa perspectiva plural. Hall e Jefferson (1983) mencionam a juventude de classe operária, tais como os teds, mods e skins; ou aquelas inspiradas nas classes médias, como os hippies e os freaks, como tentativas de enfrentamento das contradições da cultura parental, na qual ocorre a socialização primária que iria influenciar substancialmente na constituição da personalidade de cada grupo de classe e, portanto, na visão de mundo dos jovens.

De fato, há um predomínio de estudos sobre a juventude de classe operária, como observa Feixa. Os jovens de classe média seriam apenas associados a movimentos contraculturais e deveriam, portanto, ser estudados mais profundamente (Feixa, 1999, p. 93).

O desenvolvimento econômico desigual numa sociedade extremamente competitiva exige uma maior preparação para o mundo do trabalho e uma maior escolarização, que dentre outros fatores prolongam a transição do jovem ao mundo adulto. Diante disso, podem ocorrer consequências como a redução de oportunidades no sistema produtivo e, portanto, o surgimento de tipos sociais não integrados, considerados "desviantes" (Parsons, 1964). 
Teóricos como Merton (1949) consideram a "crise e a falência" de marcos institucionais e normativos da sociedade moderna, em que as metas prescritas não são alcançadas por certos indivíduos. Esse fracasso social ocorreria em função das restrições de acesso aos mecanismos institucionais de promoção social como a escola e o trabalho, causadoras da delinquência. Assim, as instituições, como a família, a escola, a Igreja e a comunidade, responsáveis pela formação e pela socialização do jovem e por sua adaptação às normas de convivência social diante da exclusão social, geram a crise de valores e, consequentemente, a perda do idealismo frente aos obstáculos do sistema.

S. N. Eisenstadt, interessado em problemas intergeracionais discutidos em seu trabalho mais conhecido sobre o tema, De geração a geração (1976), considera que o surgimento da juventude, como um grupo social específico, ocorre quando não há um perfeito ajustamento entre as regras sociais articuladas no interior da família. O autor foi responsável pela implementação de várias pesquisas de cunho teórico e empírico sobre as gerações e a juventude, influenciado pelo funcional estruturalismo norte-americano de Talcott Parsons, especialmente no que se refere ao conceito de variáveis padrão.

Dessa forma, considera-se que cada indivíduo atravessa diferentes gerações durante o seu tempo de vida. Essa premissa, relacionada ao tempo de vida e à definição de determinados estágios geracionais, será debatida exaustivamente pelo autor em sua obra. Em cada estágio da vida, ou grupos etários, há determinadas regras a serem seguidas dentro de papéis sociais específicos, tais como: a criança, o adulto e o velho. Para o autor, esses estágios, em termos biológicos, seriam praticamente os mesmos em todas as sociedades, contudo, eles seriam diversos, exatamente por serem definidos culturalmente (Eisenstadt, 1976).

$\mathrm{Na}$ relação face a face, os indivíduos assimilam seus papéis de comportamentos a ser desempenhados a cada geração, portanto, em termos de socialização, a criança aprende com o adulto as regras de conformação que a levam, mais adiante, a negar a sua condição de criança.

Por outro lado, dentro de uma lógica social competitiva, quando os valores transmitidos pela família não permitem ao jovem alcançar plenamente o status social pretendido, ele passa a se articular dentro de grupos específicos de geração (age groups). Consequentemente, todas as condições que lhe permitiriam o perfeito ajuste na estrutura social seriam consideradas como parte do processo de surgimento de grupos jovens articulados em torno de demandas específicas, tais como econômicas (trabalho, emprego, consumo). Além disso, as restrições sociais estabeleceriam o autoritarismo político e a interdição e o controle do comportamento sexual dos jovens (Eisenstadt, 1976).
A mudança geracional, como dinâmica social e fator de sua integração, nem sempre ocorre de modo 'harmônico', conforme se pode observar. Desta forma, Eisenstadt considera que a falta de realização do jovem, no conjunto de possibilidades de inserção social definidas como viáveis, provoca a criação de grupos de idade específicos. Dentro dessas coletividades, o jovem encontra a possibilidade de compartilhar e minimizar suas frustrações com outros indivíduos que sofreram a mesma "segregação social", por não terem sido admitidos numa geração ascendente, ou seja, "mais adulta". Essa organização pode permitir que ele encontre o caminho da superação de suas perdas e a consequente preparação para a "maturidade do mundo adulto", ou seja, a semi-integração no sistema social (Eisenstadt, 1976).

De fato, a abordagem de Eisenstadt, em seu apelo heurístico no sentido de demarcar diferentes categorias dos "grupos de geração", trouxe uma importante contribuição para a construção da juventude como categoria sociológica. Além disso, ampliou os horizontes da sociologia nos termos de observar determinadas relações de conflitos, parte integrante das estruturas sociais.

Ainda sobre a discussão dos grupos juvenis em Eisenstadt, há a contribuição de Groppo (2000), que enfatiza a juventude como fenômeno moderno e de caráter mais universalista. Isso especialmente no que se refere à dificuldade da juventude de se integrar de modo funcional na sociedade com um elevado grau de especialização das atividades. O papel que inicialmente caberia à família, e em segundo lugar à escola, passa a ser considerado em outros tipos de organizações, agências juvenis controladas por adultos voltadas para atividades culturais e desportivas em que os jovens pudessem gastar suas energias, entidades religiosas voltadas para a construção de valores integradores nos sistema social e até mesmo aquelas agências voltadas para tratar de "crianças-problemas", como delinquentes ou abandonadas, entre outras.

A distribuição da juventude em grupos etários e sua dificuldade no processo integrador na sociedade moderna, discutido por Eisenstadt, são algo que explicaria, segundo Groppo, o surgimento de grupos de subculturas juvenis com mais autonomia, mesmo que parcial. Além disso, observar-se-ia na contemporaneidade um maior aproveitamento dos espaços de lazer e de consumo que não eram comuns até o século XX. Isso, segundo Groppo, teria sido fundamental para a criação da cultura de massas ligada ao lazer como esporte e cultura consumidos majoritariamente pela juventude, que não caberiam em análises de períodos mais anteriores, como em Eisenstadt (Groppo, 2000, p. 55). 


\section{Estudos culturais (anos 1970)}

No contexto europeu, o Centre for Contemporary Cultural Studies (CCCS), na Universidade de Birmingham, na Inglaterra, tornou-se uma referência naquilo que ficou conhecido como estudos culturais nos anos 70 do século passado. Stuart Hall participou da criação do centro, em 1964, que também foi integrado por outros intelectuais, tais como Edward P. Thompson e Raymond Williams. Através do CCCS, surge uma nova abordagem que não incluía as tradicionais concepções psicológicas e sociológicas da juventude. Disso derivou uma historiografia de inspiração marxista combinada com uma antropologia cultural (Abma, 1992).

Em termos históricos, essa nova perspectiva de estudos das subculturas advém primeiramente de uma tradição dos estudos culturais promovidos pelo CCCS e, em segundo lugar, de uma criminologia crítica produzida pela Conferência Nacional sobre Desvio (Social), National Deviance Conference, que combinava marxismo, "abordagens americanas" e uma "teoria da reação social” (Howard Becker), além de receber uma influência do interacionismo e da etnometodologia.

Para desenvolver o conceito de estilo, diversos autores como Willis (1977), Brake (1985), Murdock (1976) e Hebdige (1979) estudaram a antiga teoria da subcultura da Escola de Chicago, bem como a etnografia. Outros autores, tais como Hall e Jefferson, focaram mais nas questões sobre as aplicabilidades da teoria marxista. Portanto, cabe assinalar que havia uma intensa discussão entre culturalistas e estruturalistas.

O centro se dedicava aos estudos relacionados à teoria da cultura, associada em alguns momentos ao compromisso político-democrático. Os campos de estudos do CCCS se constituíram de forma interdisciplinar e incluíam diversas abordagens teóricas. Havia combinações entre estudos de literatura comparada e etnografia. Nesse contexto, os estudos sobre a juventude e as subculturas britânicas, realizados por Paul Willis, foram bastante difundidos (Willis, 1977).

Paul Willis foi o membro do CCCS que se destacou no que se refere aos estudos sobre a juventude e sua inserção nos processos de mudança social. Sua obra mais conhecida nos estudos culturais e na sociologia foi Learning to labour (1977), que destaca a transição, da escola para o mundo do trabalho, da juventude de origem operária. Willis observou, em seu trabalho etnográfico, como a escola, inserida num sistema de dominação voltado para a formação de trabalhadores, não era persuasiva. Os jovens, nesse contexto, assumiam um comportamento de "oposição", marcado pelo desprezo pela escola. Portanto, eles se voltam ao culto de seus grupos de afinidade pessoal definido num estilo de vida peculiar, isso como consequência de o jovem reconhecer as desigualdades como parte de um sistema econômico capitalista, que não oferece condições iguais de mobilidade social. Willis combina, em seu estudo sobre educação jovem, aspectos relacionados à estrutura social e cultural a partir de uma abordagem etnográfica.

\section{Subculturas jovens sob uma perspectiva crítica}

Durante os anos 50 e 60, a "cultura jovem" era definida pela perspectiva do ser adolescente e gradualmente passa a ser definida em termos de outras especificidades. A "juventude" passa a ser considerada a partir dos seguintes atributos: idioma, estilo social e tipos de diversão e lazer. Amparadas por políticas do bem-estar social, a chamada generation gap transformou o sentido de classe social anteriormente baseado em fatores econômicos. A juventude passaria supostamente a se posicionar como uma nova classe em oposição ao mundo adulto (Fridenberg, 1969).

Por outro lado, outros autores (Clarke et al., citados por Abma, 1992, p. 100) consideraram essa perspectiva como um mito, porque, por trás do Estado do bem-estar social, os conflitos de classe continuavam presentes de modo muito evidente na juventude. Os jovens continuavam se agrupando em torno de valores de classe, o que os define como algo mais específico em uma subcultura. Essa dinâmica de grupos de jovens de classe trabalhadora se evidencia por dois fatores: primeiro, pelo fim de formas tradicionais de sociedade com o advento do capitalismo moderno; segundo, pelo surgimento de uma indústria jovem (teenage industry) voltada para compreender como o jovem gastava seu tempo livre em atividades de lazer. Tudo isso gerou um segmento para jovens de classe trabalhadora, incluindo-se a criação de espaços, como discotecas, clubes jovens, concertos de rock, entre outras atividades de lazer. Esses elementos compuseram a criação de uma autoconsciência da geração jovem.

Essa consciência da nova geração expressava-se numa variedade de subculturas, dependendo do grau de proximidade com os tradicionais padrões de cultura parental. Essas subculturas, por um lado, criavam uma ponte, imaginária e simbólica, entre tradição e modernidade. Além disso, elas resistiam à infiltração e à supressão da cultura da classe trabalhadora pela cultura dominante. Sua cultura de protesto não era verbal, tampouco política, contudo, era manifestada em rituais pelo idioma e pela aparência da juventude.

Nesses termos, um estilo pode ser considerado como uma mistura de elementos advindos da cultura do lazer para a juventude nos termos de uma indústria jovem. Como forma para descrever isso, Clarke 
(1976) recorreu ao termo bricolage, do estruturalismo de Lévi-Strauss, que se refere originariamente como formas mágicas utilizadas por "povos primitivos" podem ser vistas intrinsecamente de modo coerente, "recobrindo" seu usuário de significados. Os objetos e as práticas nesse contexto são capazes de promover uma infinita extensão, porque elementos básicos podem ser utilizados numa variedade de combinações improvisadas, fonte geradora de novos significados (Clarke, 1975), que serão contrastados na relação face a face com outros estilos culturais.

Cohen (1972), por sua vez, menciona quatro componentes essenciais para o desenvolvimento do estilo subcultural: vestimenta, música, ritual e linguagem. Apesar da influência de uma indústria cultural, havia a possibilidade de ressignificação desses bens materiais por parte dos seus consumidores para além da cultura dominante. Cabe assinalar que nem todas as subculturas estavam alinhadas como uma perspectiva de classe operária, mas se definiam também por sua capacidade de criação de grupos específicos.

Apesar da dificuldade do CCCS de demarcação de um campo teórico de pesquisa e da resistência que alguns setores acadêmicos têm em relação à aplicabilidade de uma metodologia marxista, pode-se afirmar que as pesquisas sobre juventude continuam sendo norteadas pelas contribuições dos Estados Unidos e do CCCS. Além disso, o CCCS ficou conhecido por uma nova abordagem crítica iniciada no debate e com correntes dominantes de uma sociologia e uma psicologia do adolescente. Essa posição foi baseada num criticismo reunido em torno da promessa de uma nova perspectiva de teoria e pesquisa "antiburguesa" e "antipositivista", que se opunha à generalização de uma imagem negativa da juventude.

\section{Juventude como categoria social no Brasil}

Já nos idos dos anos 50 e 60, quando o Brasil já supunha estar em pleno desenvolvimentismo econômico, com um setor industrial em expansão, cresce a noção de que o Brasil, assim como a América Latina, teria se inserido numa ordem capitalista. Ao mesmo tempo, surgem diversas críticas, que evidenciavam, apesar do franco desenvolvimento, que o Brasil continuava com uma grande parcela de "destituídos sociais", conforme Fernandes (1967).

Nesse momento, a situação de desigualdade social no Brasil aparecia a partir da mudança em sua estrutura espacial e demográfica, com a urbanização e o aumento do trabalho assalariado nas cidades.
Apesar das poucas pesquisas sobre juventude de classe popular nos anos 70, cabe ressaltar o trabalho de Madeira (1986) sobre juventude urbana paulista. Nesse contexto, observou-se nos anos 70 um aumento na contratação de empregados na faixa de idade entre 10 e 17 anos, em torno de $48 \%$ em relação à população economicamente ativa (PEA) urbana (Madeira, 1986, p. 18). Por outro lado, em termos educacionais, observa-se que mais de $50 \%$ da população analfabeta estava na faixa etária de 15 a 24 anos (Madeira, 1986, p. 26). Dessa forma, as estratégias de sobrevivência familiar, que motivaram uma maior frequência da população jovem no mercado de trabalho, criaram novos fluxos em relação ao consumo e consequentemente novas dinâmicas de crescimento ou acesso à identidade juvenil das classes populares.

O Brasil, em vias de sua modernização, deveria, sob o novo discurso hegemônico, avançar em seu processo de democratização das instituições sociais. Nesse contexto, a juventude universitária merece destaque pela influência dos movimentos estudantis, que buscaram um envolvimento com os movimentos sociais das classes trabalhadoras.

Esse fenômeno no Brasil está relacionado, mesmo que em menor escala, ${ }^{1}$ ao surgimento de diversos movimentos sociais articulados pela juventude vinculados ao impacto gerado pelo pós-guerra no que se refere à modernização, especialmente ao desenvolvimento tecnocientífico. Isso estimulou uma escolarização maciça da juventude, no continente europeu e nos EUA, que teria exercido consequências na ocupação de postos de trabalho que passaram a exigir uma preparação mais demorada (Hobsbawm, 1994). Essa condição permitiu à juventude estudantil uma maior inserção política, dadas as suas condições mais favoráveis em termos de mudança social (Abramo, 1994).

Diversos movimentos sociais passaram a ser identificados como movimentos de uma juventude tida às vezes como inconformada ou rebelde como nos Estados Unidos (Searle, 2008). Na Europa, o movimento dos estudantes parisienses de maio de 1968, em Sorbonne, irrompeu uma série de manifestações de protestos por mudanças no sistema estudantil, bem como nos valores da época, como questões geracionais associadas à relação de classe, gênero e raça/etnia. Posteriormente, os estudantes obtiveram apoio de diversas instâncias dos movimentos sociais franceses, com especial ênfase do movimento operário, que na ocasião iniciou um movimento grevista em função de sua pauta reivindicatória (Hobsbawm, 1994).

Os ecos desse ativismo político, que estão relacionados a eventos em níveis transnacionais, eclodiram todo um sentimento de missão e de mudancismo nas estruturas sociais latino-americanas, inclusive na 
sociedade brasileira, expresso pelo setor universitário, em especial pela adesão dos jovens aos Centros Populares de Cultura (CPCs), ligados à União Nacional de Estudantes (UNE). Toda essa efervescência política e intelectual vivida pelo Brasil atinge diversos níveis (Holanda, 1976). Esses movimentos em geral defendiam ideais revolucionários e contrários ao regime militar iniciado em 1964. Diversas manifestações estudantis levaram à ocupação do espaço universitário, com especial destaque para as Universidades de São Paulo e de Brasília, que foram ocupadas e sofreram com a reação da polícia à época.

Apesar da relevância do quadro das juventudes de classe popular, os estudos iniciais sobre Sociologia da Juventude no Brasil estiveram mais voltados para estudos sobre a classe média universitária. Em alguns trabalhos, como em Ianni (1968), criam-se certos estereótipos em relação ao suposto desinteresse pela política do jovem das classes trabalhadoras. Alem disso, também invisibilizava-se toda uma densidade das relações sociais orientadas por dinâmicas relacionadas, como as questões de gênero e raça. Ianni $(1968)^{2}$ também abordou o jovem universitário, sob a perspectiva das classes médias. Geralmente esses estudos chegavam a conclusões em que se considerava o jovem universitário "mais politizado", ou por ter acesso a mais informação, ou pelo próprio contexto acadêmico, que suscita a reflexão da questão política de uma maneira mais "profunda" em relação ao operário semialfabetizado das fábricas.

No caso brasileiro, parte dessa juventude tratada nas análises assumiu, em contextos autoritários como o do regime militar da segunda metade do século XX, a "missão" por realizar a transformação do país, por meio do movimento estudantil de caráter revolucionário. Esses "radicais" normalmente advindos das ciências humanas, que seguiam de maneira intensa seus ideais de transformação social, não o faziam por sofrerem as consequências objetivas do sistema econômico, das quais são críticos, mas por serem influenciados por uma ideologia esquerdista que circulava nos meios universitários. Isso é preponderante para manter um sistema de distinção social. Por um lado, uma elite intelectual universitária, que chamava para si a responsabilidade de liderança pautada em perspectivas universalizantes de transformação social de um marxismo europeu. Por outro, havia o povo semialfabetizado, proletário, composto de uma massa homogênea e considerado incapaz de se organizar politicamente (Ianni, 1968).

Marialice Foracchi (1972), autora pioneira nos estudos sobre juventude no Brasil, traz uma série de contribuições em termos de análise dos processos de socialização e inclusão da juventude no mundo adulto, em especial sobre o jovem universitário e seu envolvimento com o movimento estudantil. Além disso, a autora demonstra como esse processo pode ser conflituoso em função da rebelião que compõe o comportamento juvenil. Foracchi (1972) analisou, baseando-se na perspectiva de Mannheim, como uma mesma situação de classe propicia uma geração com valores semelhantes, como no caso dos estudantes universitários. Além disso, a autora considera que a relativa condição de liberdade, pelo desprendimento do mundo do trabalho garantido pelo apoio financeiro advindo de suas famílias de classe média, os fazia mais "livres" para se dedicar a questões como a militância política. Foracchi identifica uma "nova crise" como consequência de uma suposta "marginalização temporária", dada a condição de crise vivida pelo estudante, ou seja, não ser mais adolescente e tampouco adulto, aquele que enfrenta de frente a vida imposta pelo sistema (Foracchi, 1972, p. 30).

A "recusa pelo sistema" está relacionada à possibilidade de realização de metas ainda não alcançadas previamente pelas gerações anteriores, que pode passar até pela destruição do sistema atual. A autora considera o jovem universitário como o "mais sensibilizado", porém o "menos preparado" para realizar as mudanças que propõe. Por outro lado, ela reforça ainda estereótipos sobre o suposto baixo nível de envolvimento que os jovens de origem trabalhadora demonstram pelo interesse no engajamento político, já que eles advêm de um ambiente de "pobreza cultural" (Foracchi, 1972, p. 44).

De fato, os movimentos juvenis europeus e norte-americanos influenciaram as primeiras publicações sobre uma Sociologia da Juventude no Brasil (Brito, 1968). Os estudos de Ianni (1968) e Foracchi (1972) também corresponderam a essa tendência das juventudes dos setores médios. Nesse caso, a ênfase no movimento estudantil e na sua forma específica de organização levou à elaboração de hipóteses sobre a juventude de classe popular que apontavam para um suposto desinteresse ou mesmo uma incapacidade dos jovens no sentido de alguma mobilização de cunho político reivindicatório.

Dessa forma, é possível afirmar que os primeiros estudos sobre juventude no Brasil, até meados dos anos 70, estavam mais voltados para a análise de como os jovens se configuravam como geração numa estrutura social distribuída em termos de classe e status sociais. Abordagens à maneira dos estudos culturais, interessadas numa etnografia das subculturas juvenis, terão maior visibilidade a partir dos anos 80 e 90.

Após os estudos de Foracchi (1972) e Ianni (1968), pesquisas sobre juventude continuaram a ser produzidas principalmente na forma de teses e disser- 
tações no âmbito da pós-graduação brasileira. Durante os anos 80 e 90 foram publicados alguns trabalhos baseados na perspectiva dos estudos culturais e, por conseguinte, sobre subculturas, com destaque para algumas publicações como nos estudos sobre o movimento punk no Rio de Janeiro (Caiafa, 1985) e São Paulo (Abramo, 1994) e da cultura da festa funk, no Rio de Janeiro (Vianna, 1988).

\section{Um novo paradigma da juventude nos anos 90: violência e criminalização - Uma abordagem sobre os estudos da Unesco}

De um modo geral, os anos 90 contaram com a produção de obras de autoras como Sposito (1994), Abramo (1994), Madeira (1999), entre outras, bem como a produção de várias dissertações e teses sobre a temática da juventude. Nesse período, a temática dos estudos sobre juventude no Brasil passa a influenciar instituições como a Unesco e o próprio Estado. Nesse contexto, a Unesco contribuirá para uma articulação no que se refere ao campo institucional de pesquisas sobre juventude, que culminarão na criação de aparatos institucionais voltados à criação de políticas públicas, como a Secretaria Nacional de Juventude, em 2005 (Castro, 2005).

A intervenção da Unesco, como agente internacional polarizador, na esfera intelectual e política, será catalisada a partir da redefinição da categoria juventude, passando pela perspectiva da violência e da cidadania e do protagonismo jovem. Nesse caso, há um revisionismo de diversas abordagens sobre a categoria juventude, utilizando-se referenciais que em geral revelam o problema estrutural da violência juvenil, que passa por instituições como família, escola, mundo do trabalho, bem como valorizam perspectivas teórico-metodológicas dos estudos culturais que enfatizam o discurso jovem no contexto de sua sociabilidade nas subculturas juvenis.

De fato, a Unesco historicamente vem desenvolvendo atividades que assimilam aspectos das pesquisas com vistas a definir planos de ação intervencionistas. Dessa forma, ela objetiva conhecer e intervir no contexto no qual está inserida para a difusão daquilo que se consideram valores democráticos, a partir da instauração de "uma cultura de paz e não violência". Esses valores seriam difundidos a partir de programas em parceria com o governo federal e os Estados, como o Abrindo Espaços: Construção de uma Cultura de Paz (Castro, 2005, p. 58).
A entidade realizou também vários eventos em torno da temática da juventude, o que permitiu uma articulação entre membros da elite política, tanto em níveis locais como nacionais, e a aproximação da esfera acadêmica. Esses campos político-acadêmicos, ao serem articulados, foram capazes de colaborar com a construção de um novo sentido de juventude, a exemplo da divulgação da Unesco de alguns resultados de suas pesquisas sobre o tema, como feito nas publicações Jovens acontecendo na trilha das políticas públicas e Juventude, violência e cidadania (Castro, 2005). Além disso, a Unesco financiou diversas pesquisas em nível regional nos anos subsequentes. ${ }^{3}$

Essas publicações, em geral, seguiram a mesma orientação teórico-metodológica durante a realização das pesquisas. A única ressalva fica para o Mapa da violência (Waiselfisz, 1998b), uma pesquisa quantitativa de abrangência nacional, que se tornará uma referência para muitos estudos posteriores sobre o tema.

Esse montante de publicações expressa o sentido de uma mobilização de um grupo de intelectuais no caminho da (re)definição de um campo de pesquisa, difusor de imagens e conceitos em relação à juventude como categoria social e como objeto de pesquisa, que ultrapassa o campo intelectual em direção à luta política pelo reconhecimento dessas novas abordagens. Associada a essa mobilização, estava a intenção da Unesco de implementar ações intervencionistas na esfera das políticas públicas para a juventude.

Essas publicações foram ainda decisivas no que se refere à consolidação da Unesco como entidade de pesquisa. Elas também propiciaram que a Unesco adquirisse uma posterior inserção no campo da elaboração e execução de políticas de intervenção, baseada em seus conceitos de juventude, violência e cidadania.

Nesse contexto, a publicação Os jovens de Brasília (1998), de Júlio Waiselfisz, pode ser considerada uma publicação-piloto, que permitiu o estabelecimento de uma articulação entre diversas instituições, bem como uma reconstrução conceitual do que vem a ser juventude. De fato, a decisão de pesquisar os jovens de Brasília se deu em função do marcante assassinato do índio pataxó Galdino Jesus dos Santos, ocorrido na cidade, cometido por jovens de classe média alta. O livro propunha a quebra de visões do senso comum sobre a juventude, em especial das classes mais abastadas. Além disso, o autor discute como a violência juvenil vem sendo abordada pela perspectiva da juventude pobre e marginalizada.

Waiselfisz (1998) realiza uma pesquisa qualitativa com jovens oriundos do Plano Piloto e cidades-satélites, na qual são discutidas questões relacionadas 
à cidade de Brasília, à vida familiar, bem como respostas sobre valores como cidadania e violência. O autor, além disso, busca outros subsídios em índices de homicídio para definir a violência causada pelo jovem a partir de organizações criminosas e subculturas juvenis. Estas seriam as razões para o "sentimento de medo" e "fatores de risco". A definição de violência é feita de maneira ampla e difícil (Castro, 2005). O autor define a violência como um problema de teoria social e da prática política.

As pesquisas da Unesco reforçam uma cultura acadêmica que mantém o enfoque de pesquisas sobre juventude sob uma perspectiva quantitativa, como se observa em Abramovay (1999), bem como em outras instituições, como a Perseu Abramo (2003). Nessas pesquisas, tornam-se evidentes questões que não priorizam aspectos das representações coletivas produzidas pelos jovens no contexto de sua vida cotidiana. Da mesma maneira, não se consideram aspectos relacionados a gênero, raça/etnia. O resultado é que, ao se omitirem questões dessa natureza, ocorre uma invisibilidade de certos atores sociais. Alguns trabalhos que normalmente chegam à conclusão de uma "sensação de derrota" sentida pelo jovem, em especial o de grupos pobres, têm consequências diretas no que se refere à sua cultura política. Essas pesquisas estão vinculadas normalmente a uma orientação teórica que não contempla aspectos vivenciais dessa juventude.

Para a Unesco, o principal argumento no sentido da construção da juventude se assemelha às abordagens baseadas na noção de papel social e função social desviante. Dessa forma, a violência é resultado da desintegração do jovem na estrutura social. A falta de integração e o pessimismo são considerados como os principais fatores que propiciam o surgimento de novas formas subculturais. Além disso, Castro (2005) menciona fatores para o avanço de práticas criminosas, como o desenvolvimento das sociedades modernas, o acelerado ritmo de urbanização, dentre outros. A pobreza segue como fator gerador de desigualdades e do não acesso à educação ou ao emprego, entre outros. Portanto, a busca da emancipação pela oposição ao mundo adulto é contrabalanceada por movimentos estudantis reivindicatórios e pela delinquência, que leva a associação da categoria jovem, ao mesmo tempo, à condição de autor e vítima da violência.

Quando a definição de juventude e de jovem se interpenetra com os fenômenos da violência, observa-se um esquema diferente. O jovem deixa de ser pensado como um segmento em "transição" e é identificado a partir de seus comportamentos e práticas, passando a ser considerado vítima ou agressor de atos de violência e tornando-se, portanto, um sujeito político importante. $\mathrm{O}$ ator da violência - que não havia ainda sido de- finido, como visto no eixo violência - encontra no eixo juventude a sua materialidade. (Castro, 2005, p. 154)

Possivelmente um país como o Brasil sofreria mais com essa crise, dada a profunda desigualdade econômica, resultado perverso de seu rápido desenvolvimento observado nas últimas décadas.

Desta maneira, no que se refere aos estudos sobre a juventude, nos anos 90, pode-se afirmar que eles estiveram associados à participação da Unesco na formação de uma nova expertise que desenvolve uma série de abordagens no campo da pesquisa social, com vistas a propor ações intervencionistas no campo das políticas públicas para a juventude (Castro, 2005). A ideia era redefinir o jovem e a juventude num campo discursivo, de modo a produzi-lo como um "protagonista", ou seja, um ator social capaz de apresentar respostas aos problemas de violência sofridos e cometidos pelos jovens na contemporaneidade. O protagonismo é construído então como uma pedagogia democrática e pacificadora, como nos lembra a continuidade da epígrafe: "Nessa concepção, educar é criar espaços reais para que os jovens possam empreender a construção do seu ser em termos pessoais e sociais" (Castro, 2005, p. 310).

A Unesco protagonizou, portanto, a retomada da juventude como uma temática sociológica, dialogando com distintas abordagens conceituais, seja em nível estrutural, seja dando ênfase em narrativas construídas no contexto da formação dos culturas juvenis. Além disso, a Unesco contribuiu na articulação de esferas, desde a político-governamentais até setores relacionados à produção de pesquisas e, por conseguinte, de discursos sobre a juventude. Tentando apontar para o problema da violência num nível pluriclassista, de um modo geral, a questão da violência, sofrida e cometida pela juventude, como um reflexo das condições de classe, continuará a permear os discursos dos estudos subsequentes.

\section{Considerações finais}

As primeiras abordagens sobre os estudos de juventude em geral estavam mais voltadas a perspectivas funcionais de integração social do jovem inscritas no processo de socialização. Essas perspectivas influenciaram de modo marcante os primeiros estudos urbanos da Escola de Chicago, preocupados, dentre outros aspectos, com os fenômenos juvenis das gangues, do desvio social e de sua relação com os processos de adaptação à vida metropolitana.

O problema da integração à estrutura social (Parsons, 1942) do jovem nos anos 40 e 50, a partir do conceito de gerações, articula o tempo de 
vida cronológico ao tempo de vida e à transmissão de valores (Eisenstadt, 1976). Problemas relacionados a uma cultura juvenil em termos de classe social e status só vão adquirir maior relevância após a Segunda Guerra Mundial.

A partir dos estudos culturais implementados pelo CCCS no final dos anos 60, ocorre com maior veemência uma crítica a abordagens estruturalistas centradas na relação entre papéis sociais. O CCCS valoriza a pesquisa etnográfica associada à ênfase nas relações de produção trazidas pela teoria marxista, combinadas no estudo das subculturas juvenis. Aspectos relacionados ao estilo social, a tipos de diversão e lazer decorrentes de políticas de bem-estar sociais criam novas condições para a juventude se posicionar como uma "classe social" em oposição ao mundo adulto.

O Brasil, no contexto latino-americano, a partir dos anos 60 e 70, sofre mudanças na sua estrutura social advindas da industrialização e da rápida e crescente urbanização. Os reflexos em termos das desigualdades sociais são observados, com o aumento da participação da juventude no mercado de trabalho assalariado urbano. Essa juventude de classe popular analfabeta ou semianalfabeta é peça-chave nas estratégias familiares para a obtenção do sustento nas grandes cidades brasileiras (Madeira, 1986). Os estudos sobre juventude no país, apesar de não enfatizarem o surgimento de subculturas como no CCCS, já remetem a problemas do mundo do trabalho enfrentados desde a juventude.

Outra vertente desenvolvida na direção de uma Sociologia da Juventude no Brasil esteve voltada para o estudante universitário localizado na classe média, que, dada a sua relativa condição de liberdade e pelo prolongamento do período de escolarização, encontrava maiores possibilidades de envolvimento com os movimentos sociais (Foracchi, 1972). Por outro lado, essa condição seria mais restrita no contexto de uma juventude de classe popular, já inserida no mercado de trabalho e, portanto, menos ociosa.

A partir dos anos 80 e 90, há uma maior diversificação em termos teórico-metodológicos nos trabalhos sobre a juventude no Brasil, com uma maior influência dos estudos culturais e o interesse pelas diversas subculturas juvenis, bem como pela dinâmica de inserção da juventude no mundo do trabalho e dos problemas relacionados a violência e escolarização da juventude.

No final dos anos 90, a Unesco trouxe uma contribuição aos estudos sobre juventude no Brasil. Nesse caso, a juventude, como categoria social, é redefinida não a partir da perspectiva de classe, mas pela abordagem de categorias, tais como violência, cidadania e protagonismo social. A Unesco, com seu ímpeto intervencionista, mobilizou pesquisadores, bem como o campo político institucional, e definiu novos parâmetros em relação à juventude. Esta deixa de ser "desviante", como em abordagens mais tradicionais, e passa a agente social, vítima e causadora da violência, o que a inclui numa perspectiva de vulnerabilidade social.

Além da Unesco, como instituição que vai motivar a redefinição dos estudos sobre juventude no Brasil, nos anos 90, observa-se o surgimento de novas abordagens sobre gerações e juventude que se posicionam de um modo crítico em relação a outras abordagens mais tradicionais. Em relação a isso, autoras como Sposito (1994) e Pais (2005), dentre outros, discutem uma abordagem teórica e metodológica considerando a juventude não simplesmente como subcultura ou sujeitos desviantes, mas levando em conta a ideia de pluralidade de suas manifestações e sua participação efetiva em termos estruturais. Esses estudos questionam as perspectivas mais tradicionais sobre os estudos da juventude. Para tanto, as autoras se voltam para a complexidade intrínseca dos modos de vida dos jovens, definidos como "culturas juvenis". Essa pluralidade cria possibilidades para novas pesquisas sobre um campo de estudos a respeito da juventude ainda em estruturação no Brasil. Aspectos como o consumo dos jovens pobres das classes trabalhadoras, bem como dimensões relativas à construção de um sistema de distinções sociais, pautados em categorias como raça-etnia, gênero e sexualidade, desafiam a construção de uma metodologia explicativa desses fenômenos presentes nas orientações coletivas das juventudes. 


\section{Referências}

ABMA, Ruud. Working-class heroes: A review of the youth subculture theory of the centre for contemporary culture studies. In: MEEUS, Wimi et al. Adolescence, careers and cultures. New York: Walter de Gruyter, 1992.p. 99-111. ABRAMO, Helena W. Cenas juvenis: punks e darks, no espetáculo urbano. São Paulo: Página Aberta, 1994.

ABRAMOVAY, Miriam et AL (Orgs.). Gangues, galeras, chegados e rappers: juventude, violência e cidadania nas cidades da periferia de Brasília. Rio de Janeiro: Garamond, 1999.

Escola de paz. Rio de Janeiro: UERJ, 2001.

(Org.). Abrindo espaços Bahia: avaliação do programa . Brasília: Unesco, Observatório de Violência nas Escolas, Universidade Católica de Brasília, Unirio, 2003.

ABRAMOVAY, Miriam; RUA, Maria das Graças. Violências nas escolas. Brasília: Unesco, 2002.

BARREIRA, César (Coord.) Ligado na galera: juventude, violência e cidadania na cidade de Fortaleza. Brasília: Unesco, 1999.

BRAKE, M. Comparative youth culture: The sociology of youth culture and youth subcultures in America Britain and Canada. London: Routledge \& Kegan Paul, 1985.

CAIAFA, Janice. Movimento punk na cidade: a invasão dos bandos sub. Rio de Janeiro: Jorge Zahar, 1985.

CASTRO, João Paulo. Unesco - Educando os jovens cidadãos e capturando redes de interesses: Uma pedagogia da democracia no Brasil. Tese (Doutorado em Antropologia) - Programa de Pós-Graduação em Antropologia Social. Museu Nacional - Universidade Federal do Rio de Janeiro, Rio de Janeiro, 2005.

CLARKE, J. HALL, S, JEFERSON (Org.). Resistence through ritual: youth subcultures in post-war Britain. London: Hutchinson, 1976. p. 9-74.

CLARKE, John. Style. In: HALL, Stuart; JEFFERSON, Tony (Org.). Resistance through rituals: youth subcultures in post-war Britain. London: Hutchinson; University of Birmingham: The Center of Contemporary Cultural Studies, 1975. p. 147-161.

COHEN, S. Folk devils and moral panics: The Creation of the Mods and Rockers. Oxford: Martin Robertson, 1972. EISENSTADT, S. N. De geração a geração, São Paulo, Perspectiva, 1976. (Coleção Estudos, 41).

Grupos informais e organizações juvenis nas sociedades modernas. In: BRITO, S. (Org.). Sociologia da juventude, I. Rio de Janeiro: Jorge Zahar, 1968. p. 37-68. FEIXA, Carles. De jovenes bandas e tribus: antropologia de la juventud. Barcelona: Editorial Ariel S.A., 1999.

FERNANDES, F. A integração do negro na sociedade de classes. São Paulo: Dominus, 1967.

FLITNER, A. Os problemas sociológicos nas primeiras pesquisas sobre a juventude. In: BRITO, S. (Org.). Sociologia da juventude, I. Rio de Janeiro: Jorge Zahar, 1968. p. 37-68.
FORACCHI, M. Juventude na sociedade moderna. São Paulo: Pioneira, 1972.

GROPPO, Luis Antonio. Juventude: ensaios sobre sociologia e história das juventudes modernas. Rio de janeiro: Difel, 2000.

HALL, Stuart; JEFFERSON, Tony (Eds.). Resistance Through Rituals: YouthSubculture in post-war Britaisn, Hutchinson, Londres. Working papers in Cultural Studies, University of Birmingham, 1983.

HEBDIGE, Dick. Subculture: The meaning of Style. London: Methuen \& CO LTD, 1979.

HOBSBAWM, Eric. A era dos extremos: o breve século XX (1914-1991). São Paulo: Companhia das Letras, 1994.

HOLANDA, Sergio Buarque de. Raízes do Brasil. Rio de Janeiro: José Olympio, 1976.

IANNI, O. O jovem radical. In: BRITO, S. (Org.). Sociologia da juventude, I. Rio de Janeiro: Jorge Zahar, 1968. p. 225-242.

INSTITUTO DE HOSPITALIDADE, SEBRAE. Projeto Juventude/Instituto Cidadania: perfil da juventude brasileira, 2003.

MADEIRA, Felicia Reicher. Os jovens e as mudanças estruturais na década de 70: Questionando pressupostos e sugerindo pistas. Cadernos de Pesquisa, $\mathrm{n}^{\circ}$ 58, p. 15-48, ago., São Paulo, 1986.

MADEIRA, M. A. B. G. Música, estilo e cultura urbana: juventude brasiliense dos anos 90. In: TORRES, Rodrigo (Org.). Musica popular em America Latina - Actas Actas do. II Congresso Latinoamericano (IASPM). Santiago, Chile: Fondart, Ministerio de Educación de Chile, v. 1, p. 270289, 1999.

MERTON, K. Robert. Social theory and social structure. New York: Enlarged Edition, The Free Press, [1949]1968. MINAYO, Maria Cecília de S. et al. Fala galera: juventude, violência e cidadania na cidade do Rio de Janeiro. Rio de Janeiro: Garamond, 1999.

MURDOCK, G., \& McCron, R. Consciousness of class and consciousness of generation. In: STUART HALL \& JEFFERESOn (Org.). Resistence throught rituals: youth subcultures in Post war Britain. London: Hutchinson, 1976, p. 192-207.

PAIS, José. Ganchos, tachos e biscates: jovens, trabalho e futuro. Lisboa: Âmbar, 2005.

PARSONS, Talcott. Age and sex in the social structure of USA. American Sociological Review, v. 7, nº 5, p. 604-616. Oct., 1942.

Youth in the context of American Society in youth: change and challenge. Daedalus, v. 91, nº 1, Winter, p. 97-123, 1962.

1964.

Essays in sociological theory. New York: Free Press,

SALLAS, Ana Luisa F. et al. Os jovens de Curitiba: esperanças e desencantos. Brasília: Unesco, 1999. 
SEARLE, John. Philosophy in a new century: Selected Essays. United Kingdom: Cambridge, 2008.

SHAW, Clinfford. The Jack-roller. Chicago, Ilinois: Ed. University of Chicago Press, 1966.

SPOSITO, Marília Pontes. A sociabilidade juvenil e a rua: novos conflitos e ação coletiva na cidade. Tempo Social Rev. Sociol, v. 5, no 1-2, p. 161-178, 1994.

THRASHER, Frederick. The gang: a study of gangs in Chicago. Chicago: University of Chicago Press, 1927.

VIANNA, Hermano. Mundo funk carioca. Rio de Janeiro:
Jorge Zahar, 1988.

WAISELFISZ, Júlio J. (Coord.). Juventude, violência e cidadania: os jovens de Brasília. São Paulo: Cortez, 1998.

Mapa da violência contra os jovens do Brasil. Rio de Janeiro: Garamond, 1998b.

WHYTE, William Foote. Sociedade de esquina. Rio de Janeiro: Jorge Zahar, 2005. 390 p.

WILLIS, Paul. Learning to labor: How working class kids get working class jobs. New York: Columbia Univ. Press, 1977.

\title{
Sociology of Youth: from deviant youth to Unesco youth protagonism
}

\begin{abstract}
This article discusses theoretical approaches on youth studies developed by the School of Chicago: structural functionalism and cultural studies. It also analyzes some pioneering youth studies in Brazil. This scenario reveals an emphasis on middle class youth studies and an absence of researches on youth working class; fact that has changed since the end of the nineties, when Unesco assumed a social demand for studies on youth. Being mobilized by academic scholars and policy managers, this organization has given this research field a new impetus that now assumes a multidisciplinary approach.
\end{abstract}

Key words: structural functionalism, cultural studies, Sociology of Youth in Brazil, Unesco.

\section{Sociología de la Juventud: de la juventude desviante hasta lo protagonismo joven de la Unesco}

\section{Resumen}

En este artículo discute algunos aportes teóricos para los estudios de la juventud desarrollados por la Escuela de Chicago, la teoría estructural-funcionalista y los estudios culturales. Por otra parte, algunos estudios pioneros en la juventud en el Brasil serán analizados. Este panorama divulga cierto énfasis en estudios de las juventudes de las capas medias y por otra parte, cierta ausencia de la investigación sobre la juventud trabajadora. Este cuadro, alternadamente, sufrirá una alteración de los estudios de la Unesco en el final de los años noventa, al si se asume que una demanda social para los estudios en la juventud. De hecho, la Unesco movilizó doble para los investigadores académicos y de manejos público de la política este campo de la investigación que asume actualmente una posición al multidisciplinar.

Palabras-clave: estructuralismo, estudios culturales, Sociología de la Juventud en Brasil, Unesco.

Data de recebimento do artigo: 17/10/2011

Data de aprovação do artigo: 22/01/2012 